\title{
Prevalence and Antibiogram of MRSA Isolated from Patient Samples and Health Care Workers in a Tertiary Care Hospital, Puducherry, India
}

\author{
S. Pramodhini ${ }^{1}$, S. Stephen ${ }^{1 *}$, J. Shanmugam ${ }^{1}$ and K. Renuka ${ }^{2}$ \\ ${ }^{1}$ Department of Microbiology, Mahatma Gandhi Medical College \\ and Research Institute, Puducherry, India \\ ${ }^{2}$ Kasturba Gandhi Nursing College, Puducherry, \\ Sri Balaji Vidyapeeth (Deemed to be University), India \\ *Corresponding author
}

\section{A B S T R A C T}

\section{Keywords}

Methicillin

resistant, Nasal

swab, Prevalence,

Multidrug resistant,

Virulence.

Article Info

Accepted:

12 October 2017

Available Online:

10 December 2017
MRSA is of serious concern in health care settings as the organism is not only resistant to methicillin but also to many other antimicrobials used for treatment. This study has been carried to determine the prevalence and antibiotic susceptibility of MRSA isolated from patient samples and health care workers. A prospective analytical study carried out on 450clinical samples from patients and 100 nasal swab from health care workers in tertiary care hospital, Puducherry. All Staphylococcus aureus isolates identified by conventional phenotypic methods were screened for methicillin resistance by Cefoxitin disc diffusion test. Out of 450 pus samples, 90(20\%) were Staphylococcus aureus, of which, 30(33.3\%) were methicillin resistant. Out of 100 nasal swab screened from health care workers, $18(18 \%)$ were Staphylococcus aureus, of which $5(27.8 \%)$ were methicillin resistant. All the MRSA isolates were found to be $100 \%$ sensitive to vancomycin, teicoplanin and linezolid. Treatment of multi drug resistant MRSA is still problematic because of limited choice of antibiotic and the option of drug for empirical therapy for staphylococcal infections depends on susceptibility data for the local geographic area.

\section{Introduction}

Staphylococci spp are the major groups of bacteria inhabiting the skin, skin glands, and mucous membranes of humans. Among these, Staphylococcus aureus is the most common pathogen causing suppuration, abscess formation, pyogenic infections, and even fatal septicemia. Staphylococcus aureus has got the tendency to develop resistance to many antimicrobial agents and present with therapeutic difficulty.

Methicillin resistant Staphylococcus aureus (MRSA) was initially confined to the hospital setting. In present scenario, community associated MRSA (CA-MRSA) has emerged, particularly in younger patients as cause of skin and soft tissue infections and necrotizing pneumonia. CA-MRSA isolates are considered more virulent, characterized by the presence of the Panton-Valentine leukocidin and Staphylococcal Cassette Chromosome mec type IV, which may explain the increased susceptibility to other antimicrobials as compared to hospital acquired MRSA strains.

The region wise incidence of MRSA shows, $25 \%$ in western part of India (Patel et al., 2010) to $50 \%$ in South India (Gopalakrishnan 
and Sureshkumar, 2010). Few expensive drugs like vancomycin, linezolid, daptomycin, teicoplanin, and streptogramins are the current drug of choice for MRSA.

This study has been carried to determine the prevalence and antibiotic susceptibility pattern of MRSA isolated from patient samples and health care workers.

\section{Materials and Methods}

This prospective analytical study was carried out for a period of one year. Samples included in this study were 450 pus samples from patients and 100 nasal swab from health care workers in tertiary care hospital, Puducherry. Samples were inoculated into Blood agar and MacConkey agar.

Staphylococcal isolates were identified by conventional phenotypic methods such as colony morphology, Gram's stain, catalase test, slide and tube coagulase test, growth on Mannitol salt agar and DNase production. (Collee et al., 1996)

\section{Antimicrobial susceptibility testing methods}

Bacterial susceptibility to antimicrobial agents was determined by Kirby Bauer disc diffusion method on Mueller Hinton agar plates with commercially available discs (HiMedia, Mumbai). Isolates were categorized as susceptible, intermediate and resistant, based upon interpretive criteria developed by the Clinical and Laboratory Standards Institute (CLSI). Antibiotic discs (Hi-Media) Penicillin $(10 \mu \mathrm{g})$, Erythromycin $(10 \mu \mathrm{g})$, Tetracycline $(10 \mu \mathrm{g})$, Gentamicin $(10 \mu \mathrm{g})$, Cotrimoxazole $(1.25 / 23.75 \mu \mathrm{g}), \quad$ Ciprofloxacin $(5 \mu \mathrm{g})$, Erythromycin $(15 \mu \mathrm{g})$, Cefoxitin $(30 \mu \mathrm{g})$, Linezolide $(30 \mu \mathrm{g})$, and Vancomycin $(30 \mu \mathrm{g})$ were used for antimicrobial susceptibility tests.

\section{Detection of MRSA}

All Staphylococcus aureus isolates were screened for MRSA by Cefoxitin disc diffusion testing. The results were interpreted according to CLSI guidelines 2013. An inhibition zone diameter of $\leq 21 \mathrm{~mm}$ was reported as methicillin resistant and $\geq 22 \mathrm{~mm}$ was reported as methicillin sensitive.

\section{Results and Discussion}

In our study, out of 450 pus samples, 90(20\%) Staphylococcus aureus isolated. Among 90 isolates of coagulase positive Staphylococci, $30(33.3 \%)$ were methicillin resistant (Table 1).

Study on antibiotic susceptibility pattern of methicillin resistant Staphylococcus aureus $(\mathrm{n}=30)$ from clinical samples is shown in Table 2. A high proportion of isolates were resistant to penicillin (100\%) and ciprofloxacin $(57.8 \%)$, while moderate resistance to gentamicin (22.2\%) and erythromycin $(28.9 \%)$ were seen. Sensitivity for Cotrimoxazole, Tetracycline, Gentamicin and Erythromycin were 81.1\%, 85.6\%, 77.8\% and $71.1 \%$ respectively. Noresistance to vancomycin, linezolide and teicoplanin were observed.

Of 100 nasal swabs screened from health care workers, 18(18\%) Staphylococcus aureus were isolated, of which, 5(27.8\%) were methicillin resistant Staphylococcus aureus (Table 3).

Study on antibiotic susceptibility pattern of methicillin resistant Staphylococcus aureus $(n=5)$ isolated from nasal swab from health care workers is shown in Table 4. The resistant rate of isolates to penicillin, tetracycline and erythromycin were $100 \%$, $38.9 \%, 27.8 \%$ respectively. Least resistance of $11.1 \%$ was shown for ciprofloxacin and 
gentamicin, and 5.6\% to co-trimoxazole. All were sensitive to vancomycin, linezolide and teicoplanin

Staphylococcus aureus, the most virulent of many staphylococcal species, still remains a major cause of morbidity and mortality worldwide despite the availability of numerous antistaphylococcal antibiotics. This organism is responsible for both nosocomial and community-based infections ranging from minor skin and soft tissue infections to lifethreatening systemic infections. Contact spread of infection plays an important role in the hospitals, where a large proportion of the staff and patients carry antibiotic-resistant Staphylococci in the nose or on the skin.

MRSA case was reported within one year of the introduction of methicillin. Since then, the prevalence of MRSA has been steadily increasing. In many hospital settings, about $40-50 \%$ of $S$. aureus isolates are resistant to methicillin. The mechanism of methicillin resistance is due to the production of novel penicillin-binding protein (PBP2a). This protein is synthesized by the mecA gene, which is part of a large mobile genetic element - a pathogenicity or genomic island-called SCCmec.

Table.1 Isolation rate of Staphylococcus aureus from clinical samples

\begin{tabular}{|l|l|l|}
\hline Total no of samples & $\begin{array}{l}\text { Total No of Staphylococcus } \\
\text { aureus isolated from clinical } \\
\text { samples }\end{array}$ & $\begin{array}{l}\text { Percentage of Methicillin } \\
\text { resistant } \\
\text { aureus }\end{array}$ \\
\hline 450 & $90(20 \%)$ & \multicolumn{1}{|c|}{$30(33.3 \%)$} \\
\hline
\end{tabular}

Table.2 Study of antibiotic susceptibility (\%) pattern of MRSA isolated from clinical samples $(n=30)$

\begin{tabular}{|l|c|c|}
\hline Antibiotic & S (\%) & R (\%) \\
\hline Penicillin & $0 \%$ & $100 \%$ \\
\hline Cotrimoxazole & $81.1 \%$ & $18.9 \%$ \\
\hline Erythromycin & $71.1 \%$ & $28.9 \%$ \\
\hline Tetracycline & $85.6 \%$ & $14.4 \%$ \\
\hline Cefoxitin & 0 & $100 \%$ \\
\hline Ciprofloxacin & $31.1 \%$ & $57.8 \%$ \\
\hline Gentamicin & $77.8 \%$ & $22.2 \%$ \\
\hline Vancomycin & $100 \%$ & 0 \\
\hline Linezolide & $100 \%$ & 0 \\
\hline Teicoplanin & $100 \%$ & 0 \\
\hline
\end{tabular}

$\mathrm{S}=$ Sensitive $\mathrm{R}=$ Resistant

Table.3 Percentage of Staphylococcus aureus isolated from nasal swab from health care workers

\begin{tabular}{|l|l|l|}
\hline Total No of cases & $\begin{array}{l}\text { Isolates of Staphylococcus } \\
\text { aureus }\end{array}$ & $\begin{array}{l}\text { Percentage of Methicillin } \\
\text { resistant } \\
\text { aureus }\end{array}$ \\
\hline 100 & $18(18 \%)$ & $5(27.8 \%)$ \\
\hline
\end{tabular}


Table.4 Study of antibiotic susceptibility (\%) pattern of MSSA \& MRSA isolated from nasal swab $(n=18)$

\begin{tabular}{|l|c|c|}
\hline Antibiotic & S (\%) & R (\%) \\
\hline Penicillin & $0 \%$ & $100 \%$ \\
\hline Cotrimoxazole & $94.4 \%$ & $5.6 \%$ \\
\hline Erythromycin & $72.2 \%$ & $27.8 \%$ \\
\hline Tetracycline & $61.1 \%$ & $38.9 \%$ \\
\hline Cefoxitin & $72.2 \%$ & $27.8 \%$ \\
\hline Ciprofloxacin & $88.9 \%$ & $11.1 \%$ \\
\hline Gentamicin & $88.9 \%$ & $11.1 \%$ \\
\hline Vancomycin & $100 \%$ & 0 \\
\hline Linezolide & $100 \%$ & 0 \\
\hline Teicoplanin & $100 \%$ & 0 \\
\hline
\end{tabular}

$\mathrm{S}=$ Sensitive $\mathrm{R}=$ Resistant

In the current study, of 450 pus samples, 90(20\%) were Staphylococcus aureus and among these isolates 30(33.3\%) were methicillin resistant. The prevalence obtained in this study was slight than lower the prevalence of $41 \%$ reported in earlier studies in India by Joshi et al., (2013). Our prevalence was well comparably equal to other studies, which showed 32.22\%, 32.12\% and 30\% (Bilal Ahmad Mir et al., 2013; Suryadevara et al., 2017; Debnath and Chikkaswamy, 2015).

In our study on antibiotic profile of methicillin resistant Staphylococcus aureus isolated from clinical samples showed, high proportion of isolates were resistant to penicillin $(100 \%)$ and ciprofloxacin $(57.8 \%)$, moderate resistance rates to gentamicin $(22.2 \%)$ and erythromycin (28.9\%). Similar resistance and sensitivity pattern has been demonstrated by many other studies also where almost $80-90 \%$ of isolates were resistant to Penicillin and ciprofloxacin and almost $100 \%$ showed sensitivity to vancomycin, linezolide and teicoplanin (Bhatt et al., 2015; Debanath and Chikkaswamy, 2015; Tiwari et al., 2009).

In the current study, of 100 nasal swab screened from health care workers, 18(18\%) Staphylococcus aureus were isolated. The present study on prevalence of MRSA from nasal sample screened from health care workers, showed isolation of $27.8 \%$.This percentage is comparable to similar study where they have reported $23.6 \%$ MRSA isolated from surveillance cultures. Wakatake et al., (2015) and another study which reported 23.71\% from nasal samples (Sharma and Mall, 2011). Study by Sharon et al.,2013, showed that $22.22 \%$ of the HCWs carried S.aureus in their anterior nares of which $11.43 \%$ were MRSA, lower percentage recorded than our study.

Our study on the sensitivity pattern of MRSA isolated showed, $94.4 \%$ were sensitive to trimethoprim/sulfamethoxazole and $88.9 \%$ were sensitive to ciprofloxacin and gentamicin. The sensitive pattern to trimethoprim/sulfamethoxazole was similar to study by Wakatake et al., (2015) (95.4\%) and resistant pattern to Ciprofloxacin and Gentamicin were comparable to study by Mohite (2015).

To conclude, the prevalence of MRSA infection in patient and health care workers, in the present study was found to be $33.3 \%$ 
and $27.8 \%$. Increasingly, vancomycin, linezolide and teicoplanin are still the drugs of choice for both community- and hospitalacquired infections. Oral agents that effective against these isolates include clindamycin, trimethoprim- sulfamethoxazole, doxycycline, linezolid, and tedizolid (Kasper and Dennis, 2015).

Treatment of multi drug resistant MRSA is still problematic because of limited choice of antibiotic and the option of drug for empirical therapy for staphylococcal infections depends on susceptibility data for the local geographic area. In addition to it measures like cleanliness, hygiene, and aseptic management of lesions can control the spread of staphylococci from lesions as well dissemination of Staphylococci from carriers.

\section{References}

Bhatt MP, Bhalla GS, Tandel K, Jindamwar P, Chaudhari CN, Grover N, Sahni AK Antimicrobial Susceptibility Profile of Methicillin-resistant Staphylococcus aureus at a Tertiary Care Centre. Archives Of Clinical Microbiology 2015; 6(3:6).

Collee JG, Miles RS, Watt B. Tests for the identification of bacteria. In: Collee JG, Fraser AG, Marmion BP, Simmons A (eds). Mackie and McCartney Practical Medical Microbiology. $14^{\text {th }}$ edn. Edinborough: Churchill Livingstone; 1996; pp. 131- 52.

Debnath A, Chikkaswamy Bk. Antibiogram and susceptibility pattern of methicillin resistant Staphylococcus aureus collected from various clinical samples in Bengaluru. Asian J Pharm Clin Res., 2015; 8(6): 260-264.

Debnath A, Chikkaswamy Bk. Antibiogram and susceptibility pattern of methicillin resistant Staphylococcus aureus collected from various clinical samples in Bengaluru. Asian $\mathbf{J}$ Pharm Clin Res 2015; 8(6): 260-4.

Gopalakrishnan R, Sureshkumar D. Changing trends in antimicrobial susceptibility and hospital acquired infections over an 8 year period in a tertiary care hospital in relation to introduction of an infection control programme. $\mathbf{J}$ Assoc Physicians India 2010; 58: 2531.

Joshi S, Ray P, Manchanda V, Bajaj J, Chitnis DS, Gautam V, et al., Methicillin resistant Staphylococcus aureus (MRSA) in India: Prevalence and susceptibility pattern. Indian J Med Res 2013; 137: 363-9.

Kasper, Dennis L. Harrison's principles of internal medicine.19th edition / editors. New York: McGraw Hill Education Medical, [2015].

Mir AB, Srikanth. Prevalence and antimicrobial susceptibility of methicillin-resistant Staphylococcus aureus and coagulase-negative Staphylococci in a tertiary care hospital. Asian J Pharm Clin Res 2013; 6(3): 231-4.

Mohite RV. Study of Nasal Carriage of Staphylococcus aureus with Special Reference to Methicillin Resistance among Nursing Staff. Arch Clin Microbiol. 2015, 7:1.

Patel AK, Patel KK, Patel KR, Shah S, Dileep P. Time trends in the epidemiology of microbial infections at a tertiary care center in west India over last 5 years. J Assoc Physicians India 2010; 58: 3740.

Sharma S, Mall A. The prevalence, antibiogram and characterisation of methicillin resistant Staphylococcus aureus among the patients from the Doon Valley hospitals. African Journal of Microbiology Research 2011;5(21): 3446-3451. 
Sharon Rainy Rongpharpi, Naba Kumar Hazarika, Hitesh Kalita. The Prevalence of Nasal Carriage of Staphylococcus aureus Among Healthcare Workers at a Tertiary Care Hospital in Assam with Special Reference to MRSA. Journal of Clinical and Diagnostic Research. 2013 February, Vol-7(2): 257-260

Suryadevara VD, Basavaraju A, Vasireddy K. Prevalence of MRSA among clinical isolates and their antibiogram in a tertiary care hospital. J. Evolution Med. Dent. Sci. 2017; 6(21):1667-1669.
Tiwari HK, Das AK, Sapkota D, et al., Methicillin resistant Staphylococcus aureus: prevalence and antibiogram in a tertiary care hospital in western Nepal. J Infect DevCtries 2009; 3(9): 681-4.

Wakatake H, Fujitani S, Kitano Y, Lefor AT, Taira Y. Antibiogram of MethicillinResistant Staphylococcus aureus Isolates From MRSA Colonized Patients in Two Tertiary Hospital Emergency Departments. Int J Infect. 2015; 2(4): e32695.

\section{How to cite this article:}

Pramodhini, S., S. Stephen, J. Shanmugam and Renuka, K. 2017. Prevalence and Antibiogram of MRSA Isolated from Patient Samples and Health Care Workers in a Tertiary Care Hospital, Puducherry, India. Int.J.Curr.Microbiol.App.Sci. 6(12): 1419-1424. doi: https://doi.org/10.20546/ijcmas.2017.612.159 